\title{
Kripto Para Fiyatlarının Tahmininde Gri Sistem Teorisi: Yöntemsel Karşılaştırma
}

\author{
Grey System Theory For Prediction of Crypto Money Prices: Methodological Comparison
}

\section{Eyyüp Ensari ŞAHIN ${ }^{1}$ - Buğra BAĞCl ${ }^{2}$}

Başvuru Tarihi: 21.12.2019

Kabul Tarihi: 04.03.2020

Makale Türü: Araştırma Makalesi

Öz

2008 yılında temelleri atılmış olan Kiripto para kavramı, 2017 yılı Aralık ayı itibari ile 19.060 $A B D$ dolarına ulaşmış ve tanınırlı̆̆ını arttırmıştır. Bitcoin ve sayıları 2700'ü bulan diğer kripto paralar hızlı kazanç elde etmek isteyen yatırımcıların dikkatini çekmeyi başarmıştır. Bu kapsamda kripto paraların fiyatının nasıl ve ne yönde değişeceği birçok kesim tarafından araştırma konusu olmuştur. Bu çalışmanın amacı, Bitcoin, Ethereum, IOTA ve Ripple gibi farklı altyapısal özellikleri olan kripto paraların gelecek fiyatını geçmişte gerçekleşen fiyatlardan hareketle tahmin etmektir. Çalışmada Deng Ju-Long tarafindan 1980'li yıllarda ortaya atılan gri sistem teorisi ile fiyat tahminlemesi yapılmıştır. Çalışmada kullanılan geçmiş fiyatlar 11 günlük süreci kapsamaktadır. Literatüre göre kısa sayllabilecek bu süre modelin diğer modellere görece üstünlüğ̈̈nü göstermektedir. Elde edilen sonuçlara göre $\operatorname{GM}(1,1)$ model ve Rolling-GM $(1,1)$ model sonuçlarının birbirine çok yakın hata oranlarıla tahmin yaptıkları ve yapılan tahminlere ait hata oranlarının çok düşük olduğu görülmüştürr.

Anahtar Kelimeler: Bitcoin, Etheryum, IOTA, Ripple, Gri Sistem Teorisi

\begin{abstract}
The concept of cryptocurrencies, the foundations of which were laid in 2008, reached \$19,060 as of December 2017 and increased its recognition. Bitcoin and other cryptocurrencies, the number of which reaches 2700, managed to attract the attention of investors who want to make a quick profit. In this context, how and how the price of cryptocurrencies will change has been the subject of research by many segments. The aim of this study is to predict the future price of cryptocurrencies with different infrastructural features such as Bitcoin, Ethereum, IOTA and Ripple, based on the prices of the past. In the study, price estimation was made with the grey system theory introduced by Deng Ju-Long in the 1980s. The past prices used in the study cover the 11day process. This period, which can be considered short according to the literature, shows the superiority of the model over other models. According to the results obtained, it was seen that $G M(1,1)$ model and Rolling-GM(1,1) model results predicted with very similar error rates and the error rates of the predictions were very low.
\end{abstract}

Keywords: Bitcoin, Etheryum, IOTA, Ripple, Grey System Theory

\footnotetext{
${ }^{1}$ Hitit Üniversitesi İktisadi ve İdari Bilimler Fakültesi, eyupensarisahin@hitit.edu.tr, ORCID: 0000-0003-2110-7571

${ }^{2}$ Hitit Üniversitesi İktisadi ve İdari Bilimler Fakültesi, bugrabagci@hitit.edu.tr, ORCID: 0000000232683702
} 


\section{Giriş}

Bir varlığın para olabilmesi için; mübadele aracı, hesap birimi ve tasarruf aracı olma fonksiyonlarını taşıması gerekmektedir. Para, mübadele aracı olup para ile temel tüketim maddesi, menkul ya da gayrimenkul alınabilmektedir. Muhasebe işlemleri para birimi üzerinden yapılmakta, tasarruflar da para olarak saklanabilmektedir. Geleneksel anlayışa göre para, devlet olmanın olmazsa olmazlarındandır. Bir başka ifadeyle, arkasında devlet olmayan para; para olarak kabul görmemektedir. Devletler, Bitcoin, Ethereum vb. kripto paraları para birimi olarak kabul etmedikçe para olmamakta, bir hesap birimi ya da endeks olarak değerlendirilmektedir. Söz konusu endeks, alıcı ile satıcı arasındaki sübjektif bir değer olup, ülkelere ait yasalar onu "para" olarak kabul etmemektedir. Bununla birlikte kripto paraların temel çıkış noktalarından birisi de merkezi otoriteye bağlı olmadan geniş bir tabana yayılarak değer saklama ve/veya mübadele aracı olmasıdır.

Para kullanımının tarih boyunca birçok farklı türü (30 Tonluk taşların para olarak kullanılması gibi) olmuştur (Vigna ve Casey, 2015, s. 57). Bunlardan en yaygın olanları; "Emtia Para" (değerini yapıldığı hammaddeden alır), “Temsili Para” (değeri altına veya gümüşe bağlanmış kâğıt para) ve "İtibari Para" (değerini merkezi hükümet veya merkez bankasından alan para) şeklinde sınıflandırılabilir. Finansın teknoloji ile buluşması parayı çok farklı bir boyuta taşımıştır. Teknolojik bu süreç Dijital, Sanal ve Kripto para kavramını ortaya çıkarmıştır. Dijital para, elektronik olarak saklanan ve farklı kişilere transfer edilebilen paralardır. Bu tanım Sanal paralar içinde geçerlidir. Sanal para, merkezi bir hükümet ya da merkez bankası tarafından basılmış bir paranın dijital temsilidir. Kripto para ise, dijital paranın bir türüdür ancak temsil ettikleri bir merkezi hükümet ya da merkez bankası bulunmamaktadır. Özet olarak hem sanal para hem de kripto para dijital özellikte olması nedeniyle dijital bir para birimi olarak adlandırılabileceği gibi Bitcoin ve diğer kripto paraların bazı özellikli durumları neticesinde dijital paradan ayrılmaktadır (Şahin, 2018, s. 5). Bitcoin'in başarılı olması ile birlikte çeşitli kripto para birimleri de ortaya çıkmıştır. Bitcoin ile aynı tasarım yapısına sahip olup tamamen farklı bir blockchain ağı üzerinde varlığını sürdüren bu kripto para birimlerine altcoin (alternative coin) adı verilmektedir. Sayıları yaklaşık 2700'ü bulan bu kripto paralar kuruluş yapıları gereği akıllı sözleşmelere dayandığı gibi ek olarak ekosisteminde birçok kurumsal firmayı da barındırmaktadır. Şimdiye kadar birçok altcoin denemesi yapılmış olup, bunlardan çok azı küçük ölçekli de olsa bir pazar başarısı elde edebilmiş, fakat hiçbir altcoin Bitcoin'in sahip olduğu piyasa büyüklüğüne erişememiştir. Genel olarak alt coinler Bitcoin tarafindan sunulmayan ya da sunulamayan özelliklerle pazarda yer almaya çalışmaktadırlar (Usta ve Doğantekin, 2017, s. 63). Bitcoin'e benzer nitelikte üretilmiş olan ve altcoin olarak adlandırılan bugün yaklaşık olarak sayısı 2700'lere ulaşan altcoinler işlem görmektedir (Altıner, 2017, s. 134). Özellikle piyasada yatırımcı bulan ve borsalarda hacim oluşturabilen paraların Bitcoin'den bazı farkları bulunmaktadır. Bunları makroekonomik şartlardan etkilenmeyen farklı bir para politikasına sahip olması, dijital imza ile şeffaf bir yapıya kavuşması ve kurucu ya da değerini veren bir mekanizmaya sahip olmaması şeklinde sıralayabiliriz.

Öte yandan bazı altcoinler ise bu altcoinlerden farklı olarak blok zincir alt yapısına sahip değildirler. Bunlardan en çok bilineni ise IOTA'dır. IOTA, Internet of Things (Nesnelerin 
İnterneti) için tasarlanmış olan dijital bir para birimidir. Bu coin; akıllı cihazların birbirleri arasında kolay, hızlı ve de güvenli bir şekilde para alışverişi yapabilmelerini sağlamaktadır.

Çeşitli altyapısal özellikleri itibari ile birbirlerinden ayrılmış olan kripto paralar literatürde para ya da bir emtia şeklinde birçok çalışmaya konu olmuştur. Çalışmalara ek olarak ABD SEC'de emtia şeklinde işlem görmeye başlaması kripto paralara olan güveni artırmıştır.

ABD'de finansal piyasaları düzenleme ve denetlemeye yetkili kurum olan "Menkul Kıymetler ve Borsalar Komisyonu" (Securities Exchances Commission-SEC), kripto para yatırımlarını federal ve eyalet menkul kıymet yasalarına uygun bulmamaktadır. Komisyon; kripto paraları para olarak değil emtia olarak kabul etmektedir (Brière vd., 2015; Halaburda ve Gandal, 2014; Baur ve Lucey, 2010; Öztürk vd., 2018). Bitcoin başta olmak üzere kripto paraların SEC tarafından emtia olarak görülmesi sebebiyle piyasa değerleri hızla artan kripto paralara ilgi daha da artmıştır. Söz konusu bu ilgi, yatırımcıların kripto paraların fiyatlarını tahmin etme isteğini artırmakta ve birçok analist tarafından gelecek fiyat öngörüleri üzerine teknik analiz yöntemleri uygulanmaktadır. Temelde bir menkul kıymet ya da paraya ilişkin gelecek öngörüleri makroekonomik faktörler gibi birçok değişkeni içeren büyük bir notasyonlar bütününün yorumunu gerektirmektedir. Ancak kripto paralar kuruluş yapıları gereği makroekonomik faktörlerden etkilenmemekte buna karşın fiyat hareketleri arz ve talebe bağlı olarak değişmektedir. Ek olarak haber manipülasyonları da kripto paraların fiyatını etkilemektedir.

Google Trend Data üzerinde yapılan ve Kripto Paraların fiyatı ile ilgili yapılan aramalar Sekil 1'de gösterilmiştir.

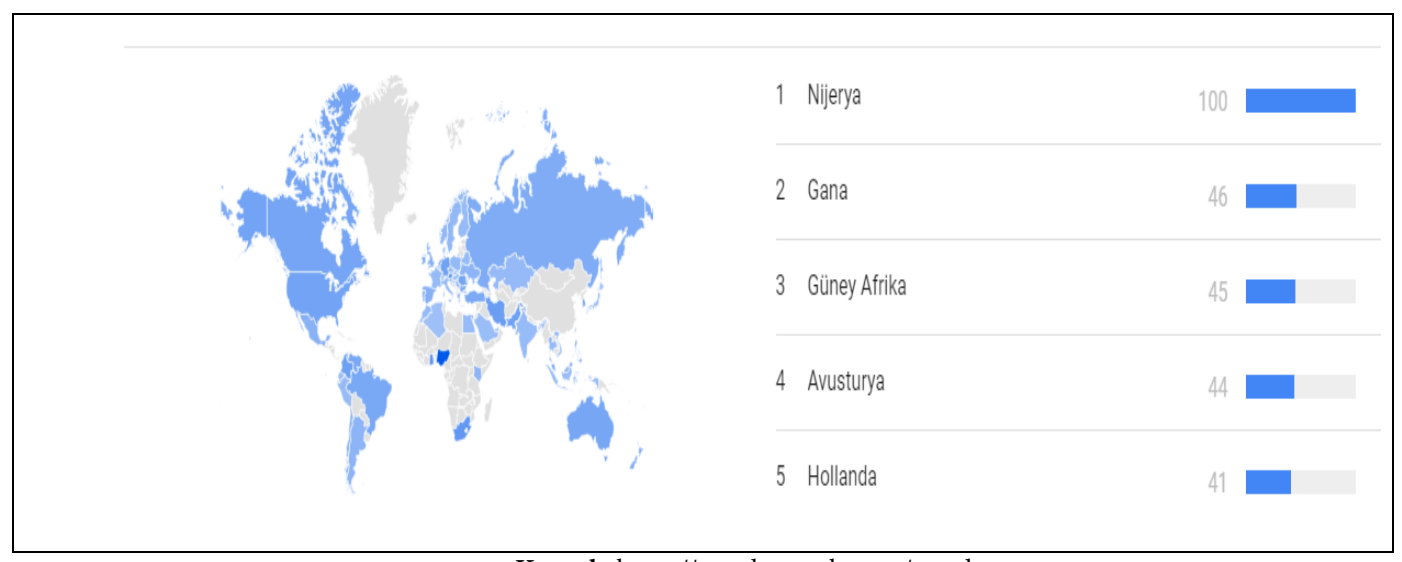

Kaynak: https://trends.google.com/trends.

\section{Şekil 1. Google Trend Data “Bitcoin Fiyatı” Dünya Geneli}

Şekil 1 incelendiğinde kripto para fiyatına ${ }^{3}$ ilişkin aramaların özellikle az gelişmiş ülkelerde yoğunlaştığı görülmektedir. Özellikle aramaların Kripto paralar ile ilgili "Bitcoin haberleri, Etheryum vb. haberleri” şeklinde yoğunlaştığ ${ }_{1}$ Google Trend Data üzerinden görülebilmektedir.

Yine aşağıda Google Trend Data üzerinden Türkiye'de “Bitcoin Fiyatı” araştırması sonucu paylaşılmıştır.

\footnotetext{
${ }^{3}$ Son beş yıla ait haberler "Dünya geneli” seçeneği seçilerek taranmıştır.
} 


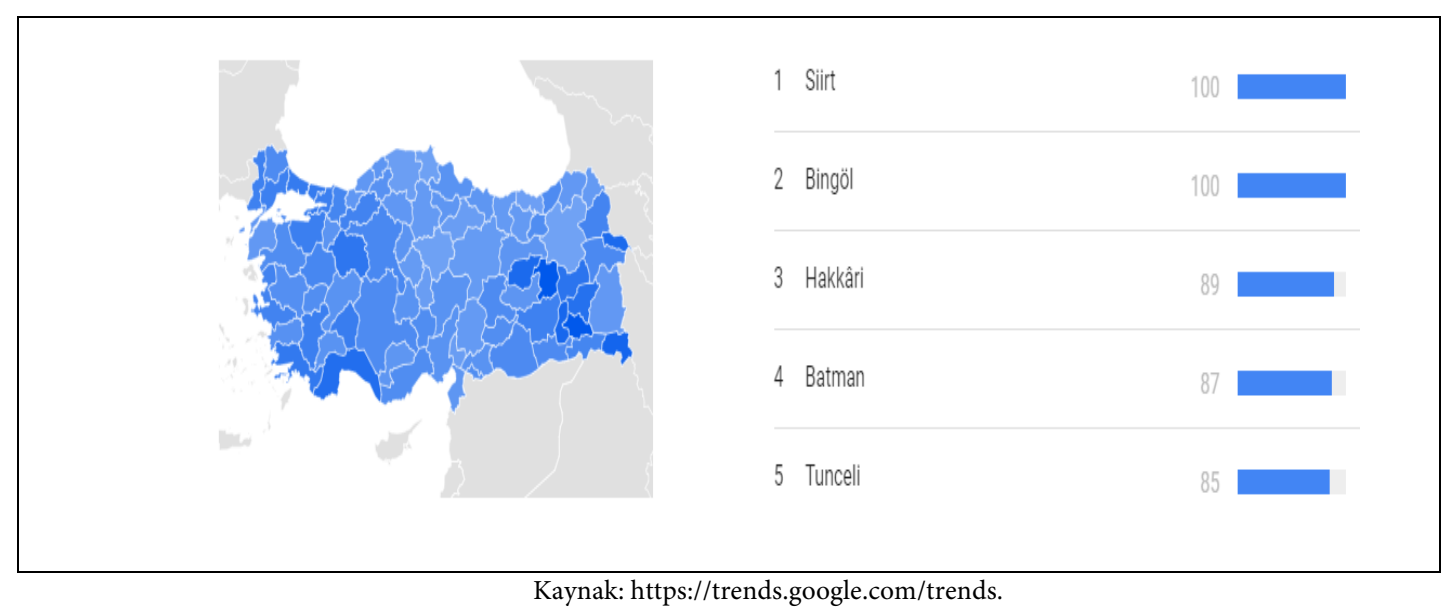

Şekil 2. Google Trend Data "Bitcoin Fiyatı" Türkiye

Şekil 2 incelendiğinde Türkiye'de "Kripto Para Fiyatı" aramaların dünya geneli aramaları ile benzerlik gösterdiği görülmektedir. Özellikle sosyo-ekonomik gelişmişlik düzeyi yönünden son sıralarda yer alan illerin kripto paralara ilişkin fiyat yönü beklentileri olduğu gözlemlenmiştir.

\section{Literatür Taraması}

Finansal piyasalar yapısı gereği fiyat oynaklığı ve beraberinde fiyatların tahmin edilebilmesi konuları ile yakından ilişkilendirilebilir. Bu kapsamda birçok ekonometrik, istatistiksel ve matematiksel modellemeler fiyat tahminlerinde kullanılmaktadır. Kripto para fiyatlarının tahminine ait literatürde yapılan çalışmalar incelendiğinde, büyük çoğunluğun sadece farklı analizler kullanarak Bitcoin fiyat tahmini yaptığı görülmektedir.

Almeida (2015), yaptığı çalışmada geçmiş fiyatları kullanarak gelecek Bitcoin fiyatını tahmin etmeye çalışmışlardır. Çalışmada yapay sinir ağları modeli kullanılmış olup, Bitcoin fiyatını tahmin etmede oldukça başarılı olduğu sonucuna ulaşmışlardır.

Sin ve Wang (2017), yaptıkları çalışmada Yapay Sinir Ağı topluluğu yaklaşımı kullanılarak Bitcoin fiyatının sonraki gün fiyatını tahminlemeyi amaçlamışlardır. 50 günlük bir süre zarfında, topluluğa dayalı bir alım satım stratejisi, geri testler aracılığıyla alım satım stratejisini izleyen "önceki gün trendiyle" karşılaştırılmıştır. Sonuç olarak, GASEN adlı topluluk yöntemi, sınıflandırma görevi için \% 58 ile \% 63 arasında tutarlı bir doğrulukla iyi bir performans sergilemiştir.

Kodama vd. (2017), yaptıkları çalışmada 23 Nisan 2015-15 Ağustos 2016 tarihleri arasında COINBASE pazarında Euro cinsinden bireysel işlemleri kaydeden Bitcoin fiyatlarına ait zaman serisi veri kümesini analiz etmişlerdir. Çalışmada tek değişkenli otoregresif model ve bağımlı karışım modelini kullanarak üç gizli durum rejimi tarafından temsil edilen değişken volatilite bölgelerini sınıflandırmak için Markov tekniğini uygulamışlarıdır. Çalışma sonuncunda, kripto para birimi serilerinin de döviz kuru zaman serisi verileri gibi tekrarlayan sinir ağlarının nedensellik çıkarımına uygulanabileceğini bulmuşlardır. 
Jang ve Lee (2017), yaptıkları çalışmada Bitcoin fiyatlarına ait zaman serilerini analiz ederek Bayesian sinir ağlarının (BNN) etkisini ortaya koymayı amaçlamışlardır. Ayrıca Bitcoin arz ve talebine derinlemesine dâhil olan Blockchain bilgilerinden en alakalı özellikleri seçerek model geliştirmişlerdir. Çalışmanın sonucunda Bayesian sinir ağını Bitcoin fiyatı zaman sürecinin modellenmesi ve tahmininde diğer doğrusal ve doğrusal olmayan modellerle karşılaştırmışlar ve BNN'nin Bitcoin fiyatına ait zaman serilerini tahmin etmede ve son Bitcoin fiyatının yüksek volatilitesini açıklamada iyi performans gösterdiğini bulmuşlardır.

Gencer (2017) yaptığı çalışmada Bitcoin fiyatını yapay sinir ağları ile tahmin etmeyi amaçlamıştır. Çalışmanın sonucunda 2018 Mayıs ayında Bitcoin fiyatını \$8,955 olarak tahmin etmiştir. Fakat, araştırmada kullanılan örneklem sayısının yetersiz olduğundan kaynaklı olarak elde edilen tahmin sonuçları başarısız olarak değerlendirilmiştir.

Amjad ve Sahah (2017), yaptıkları çalışmada geçmiş veriler ışığında gelecek fiyatları tahmin etmede matematiksel bir algoritma kullanarak ARIMA yöntemine göre daha doğru sonuçlara ulaşmışlardır. Kurdukları algoritmada Bitcoin fiyatının artması, azalması ve değişmediği varsayımı şeklinde üç durumu göz önünde bulundurmuşlarıdır. Bitcoin fiyatına ait tahmin sonuçları doğruluk oranının söz konusu yöntem sayesinde yüksek olduğunu göstermişlerdir.

Karasu (2018), yaptığ çalışmada Bitcoin’in bir günlük en yüksek ve en düşük fiyatlarından elde ettikleri zaman serisi ile kapanış fiyatı tahmini yapmışlardır. Çalışmada kullanılan kapanış fiyatı verileri 2012-2018 yılları arasını kapsamaktadır. Çalışmada LR, L-SVM ve P-SVM modelleri kullanılmış olup, farklı gecikme adımı içeren MA ve WMA filtreleri için en iyi sonucu veren tahmin modelinin gecikme sayısı 2 olan WMA filtreli P-SVM olduğu belirlenmiștir.

Sutiksno (2018), Bitcoin'in geçmiş fiyatlarını kullanarak a-Sutte Gösterge yöntemi ile ARIMA yöntemlerini karşılaştırmışlardır. Bitcoin'in geçmiş verilerinin ARIMA $(1,1,1)$ ve NNAR $(21,11)$ modeli ile tahmin edilen sonuçları ve $\alpha$-Sutte göstergesinin yaptığ tahmin sonuçları karşılaştırıldığında $a$-Sutte göstergesinin gelecek fiyatları tahmin etmeye daha uygun olduğu sonucuna ulaşmışlardır.

McNally (2018), yaptıkları çalışmada Bitcoin fiyatının USD cinsinden yönünün ne kadar doğru tahmin edilebileceğini tespit etmeyi amaçlamışlardır. Bu kapsamda zaman serileri tahmininde ARIMA ve derin öğrenme yöntemini karşılaştırmışlar ve çalışma sonucunda doğrusal olmayan derin öğrenme yöntemlerinin ARIMA tekniğiyle yapılan tahminden daha iyi performans göstermekte olduğu sonucuna ulaşmışlardır.

Velankar vd. (2018), yaptıkları çalışmada Bitcoin değerini etkileyen çeşitli parametreleri dikkate alarak Bitcoin fiyatını doğru bir şekilde tahmin etmeye çalışmışlardır. Çalışmada geçmiş beş yıl fiyatlarını kullanarak Bayesian Regresyon yöntemi ile gelecek fiyatları tahmin edilmiş ve çalışma sonucunda tahmin değerlerinin yüksek hassasiyet içerdiğini kanıtlamışlardır.

Catania vd. (2018), yaptıkları çalışmada, en büyük işlem hacmine sahip kripto para birimlerinin, Bitcoin, Litecoin, Ripple ve Ethereum'un fiyatlarını tahmin etmek için çeşitli alternatif tek değişkenli ve çok değişkenli modelleri karşılaştırmışlardır. Çalışmada öngörücüleri birleştirmek için bir dizi şifreleme denemesi uygulanmış ve tek değişkenli ve çok değişkenli model kombinasyonları önerilmiştir. Sonuçlar, tek değişkenli modellerin kombinasyonlarını kullanırken istatistiksel olarak önemli değişiklikler olduğunu göstermiştir. 
Vasilidas (2018), yaptığı çalışmada çapraz korelasyon analizi kullanılmıştır. Çalışma sonucunda Bitcoin fiyatı ile seçilmiş diğer makroekonomik değişkenler arasında güçlü bir korelasyon ilişkisi tespit edilmiştir.

Akcora vd. (2018), yaptıkları çalışmada Blockchain teknolojileri ile Bitcoin fiyatı arasındaki ilişki Granger nedensellik analizi ile test edilmiştir. Çalışma sonucunda güçlü bir nedensellik ilişkisi bulunmuştur.

Şahin (2018), yaptığı çalışmada son dönemlerde tahmin yöntemleri arasında giderek yaygınlaşan Yapay Sinir Ağları (YSA) kullanmış ve ARIMA yöntemi ile karşılaştırmıştır. Çalışma sonucunda MLP (6-3-1) modeli ile tahmin edilen fiyatların hem yönü hem de değerleri $\operatorname{ARIMA}(1,1,6)$ modeline göre daha başarılı sonuçlar vermiştir.

Lahmiri ve Bekiros (2019), yaptıkları çalışmada en çok işlem gören üç dijital para biriminin, yani Bitcoin, Digital Cash ve Ripple'ın fiyatını geçmiş verilerden hareketle tahmin etmek için derin öğrenme teknikleri kullanmışlardır. Çalışma sonunda derin öğrenmenin, kripto para birimi piyasalarının doğal kaotik dinamiklerini tahmin etmede oldukça etkili olduğu sonucuna ulaşmışlardır.

\section{Gri Sistem Teorisi}

Deng Ju-Long tarafından 1980'li yıllarda ortaya atılan gri sistem teorisi öncelikle belirsiz ve eksik bilgiye sahip sistemlerin çözümü için kullanılmıştır (Deng, 1982, s. 288). Gri sistem teorisi, ele alınan veri dizisinin doğal sürecindeki seyrini ortaya çıkarmaya ve açıklamaya çalışmaktadır (Liu vd., 2014, s. 21). Her ne kadar eksik bilgilere odaklanmış gibi görülse de gri sistem teorisi veri analizinde ve tahminlemede de önemli bir yere sahiptir. Gri tahminleme de, gri sistem teorisini baz alarak en az 4 gözlemle çalışan ve birçok alana başarıyla uygulanmış bir yaklaşımdır (Akay ve Atak, 2007, s. 1671).

\section{GM(1,1) Model}

$\operatorname{GM}(1,1)$ modeli, en temel gri sistem teorisi modellerinden olup birinci dereceden tek değişkenli bir modeli ifade etmektedir. Bu modelin tahminlemeye ait çalışmalarda başarılı sonuçlar verdiği bilinmektedir (Deng, 1989, s. 1). Kurulan modelin derecesinin birinci dereceden olması, modellemede kullanılan gri diferansiyel denklemin birinci dereceden olmasıyla ilgilidir. Modelin tek değişkenli olması durumu ise, ele alınan veri dizisinin kendi geçmiş değerlerinden etkilendiğinin düşünülerek, kendisinden farklı bir değişkenin analize alınmaması durumunu ifade etmektedir. Bu çalışmada da ele alınan $\operatorname{GM}(1,1)$ modeli aşağıda açılandığı şekilde çalışmaktadır.

İncelenen orijinal veri dizisi $X^{(0)}$ aşağıdaki şekilde ifade edilmiş olsun.

$$
X^{(0)}=\left(x^{(0)}(1), x^{(0)}(2), x^{(0)}(3), \ldots, x^{(0)}(n)\right)
$$

Burada $n$ gözlem sayısıdır.

Orijinal $X^{(0)}$ veri dizisinden, monoton olarak artan, 


$$
X^{(1)}=\left(x^{(1)}(1), x^{(1)}(2), x^{(1)}(3), \ldots, x^{(1)}(n)\right)
$$

dizisi elde edilmektedir.

Burada,

$$
x^{(1)}(k)=\sum_{i=1}^{k} x^{(0)}(i)
$$

dir.

$\mathrm{GM}(1,1)$ modelinin biçimlendirilmesi için,

$$
x^{0}(k)+a z^{1}(k)=b, \quad k=2,3,4, \ldots n
$$

denklemi oluşturulur.

Burada,

$$
z^{1}(k)=\alpha x^{1}(k)+(1-\alpha) x^{1}(k-1)
$$

dir.

Genellikle kullanılan durulaştırma tekniği eşit ağırlıklı olduğundan $\alpha=0,5$ alınır ve (5) denklemi;

$$
Z^{(1)}(k)=0,5 \cdot x^{(1)}(k)+0,5 \cdot x^{(1)}(k-1)
$$

şekline dönüşmüş olur.

Bu şekilde,

$$
Z^{(1)}=\left(z^{(1)}(1), z^{(1)}(2), z^{(1)}(3), \ldots, z^{(1)}(n)\right)
$$

dizisi elde edilir.

$\operatorname{GM}(1,1)$ gri diferansiyel denkleminin en küçük kareler tahmincisi,

$$
x^{0}(k)+a z^{1}(k)=b
$$

şeklinde tanımlanmaktadır.

Burada, GM(1,1) modeli kullanılarak tahminleme yapılabilmesi için (6) denkleminde yer alan $a$ ve $b$ parametrelerinin bilinmesi koşulu açıktır. Birçok farklı yöntemle bu parametreler hesaplanabilecektir. Fakat Wen (2004)'e göre, bu parametreleri tahmin etmenin en kullanışlı yolu en küçük kareler tahminleyicisidir.

(6) denklemi her bir $k$ için açık şekilde yazılacak olursa;

$$
\begin{aligned}
x^{0}(2)+a z^{1}(2) & =b \\
x^{0}(3)+a z^{1}(3) & =b \\
x^{0}(4)+a z^{1}(4) & =b \\
\cdots \ldots \ldots \ldots \ldots \ldots & \\
x^{0}(n)+a z^{1}(n) & =b
\end{aligned}
$$

denklem sistemi elde edilecektir. 
Elde edilen denklem takımı matris şeklinde yazılmak istendiğinde;

$$
\begin{aligned}
& B=\left[\begin{array}{cc}
-z^{(1)}(2) & 1 \\
-z^{(1)}(3) & 1 \\
\vdots & \vdots \\
-z^{(1)}(n) & 1
\end{array}\right] \\
& Y=\left[\begin{array}{c}
x^{(0)}(2) \\
x^{(0)}(3) \\
\vdots \\
x^{(0)}(n)
\end{array}\right] \\
& \hat{a}=\left[\begin{array}{l}
a \\
b
\end{array}\right]
\end{aligned}
$$

eşitlikleri yazılabilir.

(6) denkeleminden elde edilen denklem sistemi, (7) - (9) matrisleri ışı̆̆ında;

$$
Y=B \hat{a}
$$

şeklinde ifade edilebilir.

Buradan,

$$
\hat{a}=\left[B^{T} B\right]^{-1} B^{T} Y
$$

şeklinde çözüm denklemi elde edilir.

Buradan hareketle,

$$
\frac{d x^{(1)}(k)}{d t}+a x^{(1)}(k)=b
$$

eşitliğiyle verilen birinci dereceden türevlenebilir diferansiyel denklemin çözümü;

$$
x^{(1)}(t)=\left[x^{(1)}(0)-\frac{b}{a}\right] \cdot e^{-a t}+\frac{b}{a}
$$

şeklinde yazılabilir.

$x^{(1)}(t) \operatorname{nin} k$ noktasındaki çözümü;

$$
\hat{x}^{(1)}(k+1)=\left[x^{(1)}(0)-\frac{b}{a}\right] \cdot e^{-a k}+\frac{b}{a}
$$

ve dolayısıyla,

$$
\hat{x}^{(1)}(k+1)=\left[x^{(0)}(1)-\frac{b}{a}\right] \cdot e^{-a k}+\frac{b}{a}
$$

tahmin denklemi elde edilir.

Son olarak elde edilen seri tekrar;

$$
\hat{x}^{(0)}(k+1)=\alpha^{(1)} \hat{x}^{(1)}(k+1)=\hat{x}^{(1)}(k+1)-x^{(1)}(k)
$$

eşitliği kullanılarak geri birikimle orijinal haline dönüştürülür ve tahmin sonuçları elde edilmiş olur. Dolayısıyla GM(1,1) modeli ile sisteme ait verilerin tahmin değerleri elde edilmiş olur (Deng, 1989, s.5-9). 
Tahmin sonuçları elde edildikten sonra tahmin performansını ölçmek amacıyla;

$$
\varepsilon^{(0)}(k)=x^{(0)}(k)-\hat{x}^{(0)}(k), \quad k=1,2, \ldots, n
$$

eşitliği yardımı ile her bir gözlem değerine ait yapılan tahminin hatası hesaplanır. İncelenen sistemin hata payı ise;

$$
\Delta^{(0)}(k)=\left(\frac{x^{(0)}(k)-\hat{x}^{(0)}(k)}{x^{(0)}(k)}\right), \quad k=2,3, \ldots, n
$$

şeklinde hesaplanır. Sisteme ait doğruluk payının;

$$
p=\frac{\sum_{k=2}^{n}\left(1-\Delta^{(0)}(k)\right)}{n-1}
$$

eşitliğiyle hesaplanacağı açıktır (Tseng vd., 2001, s.295).

\section{Rolling GM(1,1) Model}

Rolling GM(1,1) modeli ele alınan veri dizisinin sürekli olarak ilerleyen verilerini kullanarak yeniden $\operatorname{GM}(1,1)$ modeli kurma süreci ile ilgilidir. Genel olarak $\operatorname{GM}(1,1)$ modeli $x_{0}(k), x_{0}(k+$ 1), $x_{0}(k+2)$ noktalarındaki bilgiyi kullanarak bir sonraki nokta olan $x_{0}(k+3)$ noktasındaki bilgiyi tahmin etmeye odaklanmaktadır. Rolling $\operatorname{GM}(1,1)$ modelinde ise, bu şekilde herbir sonraki noktaya ait bilgiye erişildiğinde ele alınan ilk nokta, analiz dışında bırakılarak aynı sayıda gözlemle yeniden $\operatorname{GM}(1,1)$ modeli kurulmaktadır. Yani $x_{0}(k+1), x_{0}(k+2), x_{0}(k+$ 3) noktalarına ait veriler kullanarak $x_{0}(k+4)$ noktasına ait olacak veri tahmin edilir (Wen, 2004).

Dikkat edilecek olursa burada $x_{0}(k+3)$ noktasındaki veriye ulaşıldıktan sonra $x_{0}(k)$ noktasındaki veri analizden atılmakta ve sisteme ait mümkün olduğunca sonraki verilere odaklanılmaktadır. Bu işlemler dizisine, sisteme ait son veriye ulaşılıncaya kadar devam edilir. Rolling GM(1,1) modeli bir sistemin çıktılarına ait veriler, bir ürüne ait fiyat verileri, finansal verilerde veya sosyal bilimlere ait değişkenlerde olduğu gibi uzun ve sürekli verilerin analizinde sıklıkla kullanılmaktadır (Kayacan vd, 2010, s.1787).

\section{Veri Seti}

Çalışmada farklı altyapılara sahip ve tanınırlığı yüksek olan 4 kripto para Bitcoin, IOTA, Ethereum ve Ripple kripto paralarına ait fiyatlar kullanılmıştır. Burada her bir değişkenin yani kripto paranın kendi geçmiş değerlerinden etkilendiği düşünülmüştür. Dolayısıyla her bir değişkene ait modeller ayrı ayrı kurulmuştur. Adı geçen değişkenlere ait veriler Hitit Üniversitesi kütüphanesinde bulunan Thomson Reuters veri sağlayıcısı kullanılarak elde edilmiş ve çalışmada gerçek veriler kullanılmıştır. Gri sistem teorisinin yetersiz veri ortamında da çalıştığını göstermek amacıyla değişkenlere ait yalnız 11 gözlem kullanılmıştır. Piyasa verileri için günlük gelişmelerin çok önemli olduğu düşünülmüş ve bu düşünceden hareketle çalışmada da günlük veriler kullanılmıştır. Ele alınan dönemin başlangıç tarihi 1 Aralık 2019 ve bitiş tarihi ise analizlerin yapılması dolayısıyla 11 Aralık 2019 olarak belirlenmiştir. 


\section{Analiz ve Bulgular}

Çalışmada kullanılan değişkenler ve bu değişkenlere ait veriler aşağıdaki tabloda görülmektedir.

Tablo 1. Ele Alınan Kripto Paralara Ait Tarihsel Gerçek Değerler

\begin{tabular}{lcccc}
\hline & BTC/USD & IOTA/USD & XRP/USD & ETH/USD \\
\hline 1 Aralık 2019 & $7.450,10$ & 0,21 & 0,2248 & 150,79 \\
\hline 2 Aralık 2019 & $7.350,30$ & 0,21 & 0,2192 & 148,63 \\
\hline 3 Aralık 2019 & $7.336,00$ & 0,20 & 0,2193 & 147,16 \\
\hline 4 Aralık 2019 & $7.238,20$ & 0,20 & 0,2140 & 145,36 \\
\hline 5 Aralık 2019 & $7.440,00$ & 0,20 & 0,2210 & 148,09 \\
\hline 6 Aralık 2019 & $7.588,30$ & 0,21 & 0,2254 & 148,46 \\
\hline 7 Aralık 2019 & $7.543,20$ & 0,21 & 0,2271 & 147,14 \\
\hline 8 Aralık 2019 & $7.564,60$ & 0,21 & 0,2291 & 150,42 \\
\hline 9 Aralık 2019 & $7.379,50$ & 0,20 & 0,2244 & 147,42 \\
\hline 10 Aralık 2019 & $7.254,60$ & 0,20 & 0,2226 & 145,57 \\
\hline 11 Aralık 2019 & $7.218,10$ & 0,20 & 0,2207 & 142,74 \\
\hline
\end{tabular}

Burada Aralık ayının başlangıcından sonra ilk 10 günde kısmen dalgalanmalar olsa da ele alınan dört kripto paranın hepsinde de bir düşüş gözlenmektedir. Dolayısıyla negatif eğimli bir trendin varlığından bahsetmek yanlış olmayacaktır.

Bu verilerden hareketle çalışmamızda kurulan ilk model GM(1,1) model olmuş ve daha önce de bahsedildiği üzere bu model her bir değişken için ayrı ayrı oluşturulmuştur. Buradan elde edilen analiz çıktıları, dolayısıyla her bir döneme ait $\mathrm{GM}(1,1)$ modeli ile tahmin değerleri aşağıdaki tabloda sunulmuştur.

Tablo 2. Ele Alınan Kripto Paralara Ait GM(1,1) Model Tahmin Sonuçları

\begin{tabular}{lcccc}
\hline & BTC/USD & IOTA/USD & XRP/USD & ETH/USD \\
\hline 1 Aralık 2019 & $7.450,10$ & 0,2060 & 0,2248 & 150,7900 \\
\hline 2 Aralık 2019 & $7.410,82$ & 0,2059 & 0,2191 & 148,4081 \\
\hline 3 Aralık 2019 & $7.406,47$ & 0,2053 & 0,2198 & 148,1156 \\
\hline 4 Aralık 2019 & $7.402,12$ & 0,2048 & 0,2205 & 147,8238 \\
\hline 5 Aralık 2019 & $7.397,78$ & 0,2042 & 0,2212 & 147,5325 \\
\hline 6 Aralık 2019 & $7.393,43$ & 0,2036 & 0,2219 & 147,2417 \\
\hline 7 Aralık 2019 & $7.389,10$ & 0,2031 & 0,2226 & 146,9516 \\
\hline 8 Aralık 2019 & $7.384,76$ & 0,2025 & 0,2233 & 146,6620 \\
\hline 9 Aralık 2019 & $7.380,42$ & 0,2020 & 0,2239 & 146,3730 \\
\hline 10 Aralık 2019 & $7.376,09$ & 0,2014 & 0,2246 & 146,0845 \\
\hline 11 Aralık 2019 & $7.371,76$ & 0,2009 & 0,2253 & 145,7966 \\
\hline
\end{tabular}

Elde edilen sonuçlar incelendiğinde $\operatorname{GM}(1,1)$ modeli ile elde edilen tahmin değerlerinin de gerçek verilerde olduğu gibi negatif eğimli bir trende sahip olduğu dolayısıyla modelin bu trendi sezdiği görülmektedir. 
Çalışmada kurulan bir başka model ise Rolling-GM(1,1) modeldir. Yine her bir değişkene ait ayrı ayrı Rolling-GM(1,1) modeli kurulmuş ve bu modele ilişkin tahmin değerleri ise aşağıdaki tabloda gösterilmiştir.

Tablo 3. Ele Alınan Kripto Paralara Ait Rolling-GM(1,1) Model Tahmin Sonuçları

\begin{tabular}{lcccc}
\hline & BTC/USD & IOTA/USD & XRP/USD & ETH/USD \\
\hline 1 Aralkk 2019 & $7.450,10$ & 0,206 & 0,2248 & 150,7900 \\
\hline 2 Aralık 2019 & $7.315,29$ & 0,2061 & 0,2183 & 147,8263 \\
\hline 3 Aralık 2019 & $7.332,48$ & 0,2045 & 0,2183 & 147,4815 \\
\hline 4 Aralkk 2019 & $7.349,71$ & 0,2028 & 0,2183 & 147,1375 \\
\hline 5 Aralık 2019 & $7.366,98$ & 0,2012 & 0,2183 & 146,7944 \\
\hline 6 Aralkk 2019 & $7.384,30$ & 0,1996 & 0,2184 & 146,4520 \\
\hline 7 Aralık 2019 & $7.436,79$ & 0,1999 & 0,2192 & 146,9171 \\
\hline 8 Aralık 2019 & $7.510,25$ & 0,2011 & 0,2214 & 147,4623 \\
\hline 9 Aralkk 2019 & $7.509,10$ & 0,1985 & 0,2205 & 146,8752 \\
\hline 10 Aralık 2019 & $7.572,56$ & 0,1993 & 0,2221 & 147,3802 \\
\hline 11 Aralık 2019 & $7.609,22$ & 0,1986 & 0,2227 & 147,3593 \\
\hline
\end{tabular}

Yine Rolling-GM(1,1) modelinin de gerçek verilerdeki trendi genel hatlarıyla tahmin ettiği görülmektedir. Yalnız burada her adımda veri setinin yenilenmesi dolayısıyla iniş çıkışlar da tahmin edilmeye çalışılmıştır. Çünkü Rolling-GM(1,1) modelinde her bir işlem basamağında ilk gözlem çıkarılıp, elde edilen son gözlem değeri veri setine eklenerek analiz yinelenmektedir. Yapılan bu iki farklı analiz sonucunda değişkenlere ait hata terimleri aşağıdaki tabloda gösterilmektedir.

Tablo 4. Ele Alınan Kripto Paralara Ait Farklı Modellere Göre Tahmin Hataları

\begin{tabular}{lcrrr}
\hline MODEL & BTC/USD & IOTA/USD & XRP/USD & ETH/USD \\
\hline GM(1,1) Model & 0,0140 & 0,0128 & 0,0115 & 0,0086 \\
\hline Rolling-GM(1,1) Model & 0,0176 & 0,0160 & 0,0152 & 0,0101
\end{tabular}

Burada hata terimlerinin birbirine çok yakın olduğu ama bunun yanında her iki modelde de çok küçük hata terimleriyle tahminlerin yapıldığı görülmektedir.

Hata oranlarının kabul edilebilir düzeyde olduğu görüldükten sonra kurulan modelin güvenilir olduğu ve sonraki dönem tahminlerinde kullanılabileceği anlaşılmıştır. Bu şekilde sonraki günlere ilişkin tahmin değerleri aşağıdaki tabloda yer almaktadır.

Tablo 5. Ele Alınan Kripto Paralara Ait Farklı Modellere Göre Gelecek Dönem Tahminleri

\begin{tabular}{lcccc}
\hline 12 ARALIK 2019 TAHMINİ & BTC/USD & IOTA/USD & XRP/USD & ETH/USD \\
\hline GM(1,1) Model & $7.367,44$ & 0,2003 & 0,2260 & 145,5093 \\
\hline Rolling-GM(1,1) Model & $7.640,89$ & 0,1977 & 0,2231 & 147,3183
\end{tabular}




\section{Sonuç}

$\mathrm{Bu}$ çalışmanın temel amacı, tahminleme yaparak kripto para yatırımcılarına yol göstermek ve literatürde sıkça kullanılan tahmin yöntemlerinden bu alanda kullanılmadığı tespit edilen Gri Sistem Teorisini uygulayarak tanıtmaktır. Bu çerçevede öncelikle farklı altyapılara sahip ve tanınırlığı yüksek olan 4 kripto para seçilmiş ve bunlara ilişkin fiyat verileri toplanmıştır. Verilerin analiz edilerek tahmin edilmesi hususunda ise, konvansiyonel analiz yöntemleri için geçerli olan yeterli genişliğe sahip bir örneklem büyüklügü ile analiz yapmak yerine, daha küçük verilerle de işlem yapma imkanı sağlayan ve son zamanda farklı alanlara uygulanmasıyla adından sıkça söz edilen Gri Sistem Teorisi tercih edilmiştir. Gri Sistem Teorisi içerisinde yer alan ve değişkene ait verilerin kendi geçmiş değerlerinden etkilendiği düşüncesiyle geliştirilen GM(1,1) model ve yine kendi geçmiş değerlerinden etkilendiğini kabul etmenin yanı sıra sürekli olarak son elde edilen veriler ışığında yeniden tahminler yapan Rolling-GM(1,1) model kullanılmıştır.

Elde edilen sonuçlara göre $\mathrm{GM}(1,1)$ model ve Rolling-GM(1,1) model sonuçlarının birbirine çok yakın hata oranlarıyla tahmin yaptıkları ve yapılan tahminlere ait hata oranlarının çok düşük olduğu, dolayısıyla kripto paralara ait fiyat verilerinin Gri Sistem Teorisi kullanılarak yapılan tahminlemelerde başarılı sonuçlara ulaşıldığı görülmüştür.

Çalışmaya kısıtları açısından bakıldığında, ele alınan dönemin genişliği, incelenen kripto para sayısı birer kısıt olarak sayılabilecektir.

Sonraki çalışmalara yön göstermek bakımından ise, daha geniş bir örneklem, karşılaştırma için farklı Gri Sistem modellerinin karşılaştırmaya dahil edilmesi ve hata terimlerinin modifiye edilerek daha küçük hata oranlarıyla tahmin yapılması düşünceleri verilebilir.

\section{Kaynakça}

Akay, D., ve Atak, M. (2007). Grey prediction with rolling mechanism for electricity demand forecasting of Turkey. Energy, 32(9), 1670-1675.

Akcora, C.G., Dey, A.K., Gel, Y.R. \& Kantarcioglu, M. (2018, June). Forecasting Bitcoin price with graph chainlets. Proceedings of the Pacific-Asia Conference on Knowledge Discovery and Data Mining, Springer, Cham, 765-776.

Almeida, J., Tata, S., Moser, A. \& Smit, V. (2015). Bitcoin prediciton using ANN. Neural Networks, 1-12.

Altıner, M. (2017). Kripto para: Bitcoin ve uluslararası ilişkiler. Cyberpolitik Journal, 2(4), 130147.

Amjad, M. \& Shah, D. (2017, February). Trading Bitcoin and online time series prediction. Proceedings of the NIPS 2016 Time Series Workshop, 1-15.

Bakar, N.A. \& Rosbi, S. (2017). Autoregressive integrated moving average (ARIMA) model for forecasting cryptocurrency exchange rate in high volatility environment: A new insight 
of Bitcoin transaction. International Journal of Advanced Engineering Research and Science, 4(11), 130-137.

Baur, D., Lucey, B. (2010). Is gold a hedge or a safe haven? An analysis of stocks, bonds and gold. Finance Reviews, 45(2), 217-229.

Brière, M., Oosterlinck, K. \& Szafarz, A. (2015). Virtual currency, tangible return: Portfolio diversification with Bitcoin. Journal of Asset Management, 16(6), 365-373.

Cabanilla, K.I.M. (2016). The future of cryptocurrency: Forecasting the Bitcoin-philippine peso exchange rate using SARIMA through TRAMO-SEATS.

Catania, L., Grassi, S. \& Ravazzolo, F. (2018). Forecasting cryptocurrencies financial time series.

Deng, J. L. (1982). Control problems of grey systems. Systems \& Control. Letters., 1(5), 288-294.

Detzel, A., Liu, H., Strauss, J., Zhou, G. \& Zhu, Y. (2018). Bitcoin: Predictability and profitability via technical analysis. SSRN Electronic Journal.

Dinges, C. (2018). Forecast of Bitcoin-can it become a major currency or is it just another bubble?. Available at SSRN 3110445. http://dx.doi.org/10.2139/ssrn.3110445.

Gencer, A.H. (2017). Yapay sinir ağları ile Bitcoin fiyatını tahminleme forecasting the bitcoin price via artificial neural networks. http://www.avekon.org/papers/2070.pdf .

Halaburda, H. \& Gandal, N. (2014). Competition in the cryptocurrency market. https://www.econstor.eu/bitstream/10419/103022/1/791932281.pdf.

Indera, N.I., Yassin, I.M., Zabidi, A. \& Rizman, Z.I. (2017). Non-linear autoregressive with exogeneous input (NARX) Bitcoin price prediction model using PSO-optimized parameters and moving average technical indicators. Journal of Fundamental and Applied Sciences, 9(3S), 791-808.

Jang, H. \& Lee, J. (2017). An empirical study on modeling and prediction of Bitcoin prices with bayesian neural networks based on Blockchain information. Ieee Access, 6, 5427-5437.

Karasu, S., Altan, A., Saraç, Z. \& Hacioğlu, R. (2018, May). Prediction of Bitcoin prices with machine learning methods using time series data. Proceedings of the 2018 26th Signal Processing and Communications Applications Conference (SIU), IEEE, 1-4.

Kayacan, E., Ulutas, B. \& Kaynak, O. (2010). Grey system theory-based models in time series prediction. Expert Systems With Applications, 37(2), 1784-1789.

Kodama, O., Pichl, L. \& Kaizoji, T. (2017, September). Regime change and trend prediction for Bitcoin time series data. Proceedings of the CBU International Conference Proceedings, 5 , 384-388). https://doi.org/10.12955/cbup.v5.954

Lahmiri, S. \& Bekiros, S. (2019). Cryptocurrency forecasting with deep learning chaotic neural networks. Chaos, Solitons \& Fractals, 118, 35-40. https://doi.org/10.1016/j.chaos.2018.11.014.

Liu, S.F., Yang, Y.J., Wu, L.F. \& Xie, N.M. (2014). Grey system theory and its application, 6. 
McNally, S., Roche, J. \& Caton, S. (2018, March). Predicting the price of Bitcoin using machine learning. Proceedings of the 2018 26th Euromicro International Conference on Parallel, Distributed and Network-based Processing (PDP), IEEE, 339-343.

Nakamoto, S. (2008). Bitcoin: A peer to peer Electronic Cash System, https://bitcoin.org/bitcoin.pdf.

Öztürk, M.B., Arslan, H., Kayhan, T., Uysal, M. (2018). Yeni bir hedge enstrumanı olarak Bitcoin: Bitconomi. Ömer Halisdemir Üniversitesi İktisadi ve İdari Bilimler Fakültesi Dergisi Academic Review of Economics and Administrative Sciences, 11(2), 217.

Sin, E., Wang, L. (2017, July). Bitcoin price prediction using ensembles of neural networks. Proceedings of the 2017 13th International Conference on Natural Computation, Fuzzy Systems and Knowledge Discovery (ICNC-FSKD), IEEE, 666-671.

Sutiksno, D.U., Ahmar, A.S., Kurniasih, N., Susanto, E. \& Leiwakabessy, A. (2018, June). Forecasting historical data of Bitcoin using ARIMA and $\alpha$-Sutte indicator. Proceedings of the Journal of Physics: Conference Series, IOP Publishing, 1028(1), p. 012194.

Şahin, E.E. (2018). Kripto para Bitcoin: ARIMA ve yapay sinir ağları ile fiyat tahmini. Fiscaoeconomia, 2(2), 74-92.

Tseng, F.M., Yu, H.C. \& Tzeng, G.H. (2001). Applied hybrid grey model to forecast seasonal time series. Technological Forecasting And Social Change, 67(2-3), 291-302.

Usta A. \& Doğantekin S. (2017). Blockchain 101, (1. bask1), İstanbul: İnkilap.

Üzer, B. (2017). Sanal para birimleri, (Uzmanlık Tezi), Ankara.

Vassiliadis, S., Papadopoulos, P., Rangoussi, M., Konieczny, T. \& Gralewski, J. (2017). Bitcoin value analysis based on cross-correlations. Journal of Internet Banking and Commerce, 22(S7), 1-12.

Velankar, S., Valecha, S. \& Maji, S. (2018, February). Bitcoin price prediction using machine learning. Proceedings of the 2018 20th International Conference on Advanced Communication Technology (ICACT), IEEE, 144-147.

Vigna P. \& Casey J. (2015). Kriptopara çă̆ı, (2. baskı), Ankara: Buzdağı.

Wen, K.L. (2004). Grey systems. Chia: Yang's Scientific Press.

Yang, S.Y. \& Kim, J. (2015, December). Bitcoin market return and volatility forecasting using transaction network flow properties. Proceedings of the 2015 IEEE Symposium Series on Computational Intelligence, 1778-1785.

https://coinmarketcap.com/currencies

https://trends.google.com/trends/?geo=US 